\title{
Article \\ Annotation and Molecular Characterisation of the TaIRO3 and TaHRZ Iron Homeostasis Genes in Bread Wheat (Triticum aestivum L.)
}

\author{
Oscar Carey-Fung ${ }^{+}\left(\mathbb{D}\right.$, Jesse T. Beasley ${ }^{+}(\mathbb{D}$ and Alexander A. T. Johnson *
}

Citation: Carey-Fung, O.; Beasley, J.T.; Johnson, A.A.T. Annotation and Molecular Characterisation of the TaIRO3 and TaHRZ Iron Homeostasis Genes in Bread Wheat (Triticum aestivum L.). Genes 2021, 12, 653. https://doi.org/10.3390/ genes 12050653

Academic Editor: Assaf Distelfeld

Received: 10 February 2021

Accepted: 22 April 2021

Published: 27 April 2021

Publisher's Note: MDPI stays neutral with regard to jurisdictional claims in published maps and institutional affiliations.

Copyright: (c) 2021 by the authors. Licensee MDPI, Basel, Switzerland. This article is an open access article distributed under the terms and conditions of the Creative Commons Attribution (CC BY) license (https:// creativecommons.org/licenses/by/ $4.0 /)$.

\author{
School of BioSciences, The University of Melbourne, Melbourne, VIC 3010, Australia; \\ ofung@student.unimelb.edu.au (O.C.-F.); jesse.beasley@unimelb.edu.au (J.T.B.) \\ * Correspondence: johnsa@unimelb.edu.au; Tel.: +61-3-8344-3969 \\ + Co-first authors.
}

\begin{abstract}
Effective maintenance of plant iron (Fe) homoeostasis relies on a network of transcription factors (TFs) that respond to environmental conditions and regulate Fe uptake, translocation, and storage. The iron-related transcription factor 3 (IRO3), as well as haemerythrin motif-containing really interesting new gene (RING) protein and zinc finger protein (HRZ), are major regulators of Fe homeostasis in diploid species like Arabidopsis (Arabidopsis thaliana) and rice (Oryza sativa L.), but remain uncharacterised in hexaploid bread wheat (Triticum aestivum L.). In this study, we have identified, annotated, and characterised three TaIRO3 homoeologs and six TaHRZ1 and TaHRZ2 homoeologs in the bread wheat genome. Protein analysis revealed that TaIRO3 and TaHRZ proteins contain functionally conserved domains for DNA-binding, dimerisation, Fe binding, or polyubiquitination, and phylogenetic analysis revealed clustering of TaIRO3 and TaHRZ proteins with other monocot IRO3 and HRZ proteins, respectively. Quantitative reverse-transcription PCR analysis revealed that all TaIRO3 and TaHRZ homoeologs have unique tissue expression profiles and are upregulated in shoot tissues in response to Fe deficiency. After $24 \mathrm{~h}$ of Fe deficiency, the expression of TaHRZ homoeologs was upregulated, while the expression of TaIRO3 homoeologs was unchanged, suggesting that TaHRZ functions upstream of TaIRO3 in the wheat Fe homeostasis TF network.
\end{abstract}

Keywords: homoeologs; E3-ligase; ubiquitination; hexaploid; KnetMiner; basic helix-loop-helix

\section{Introduction}

Iron $(\mathrm{Fe})$ is an essential micronutrient for plant growth, as it acts as a protein cofactor in photosynthetic electron transport, chlorophyll biosynthesis, and other cellular processes [1]. Maintaining cellular Fe homeostasis is key to plant health, as toxic concentrations of Fe lead to excess production of reactive oxygen species (e.g., free hydroxyl radicals) via the Fenton reaction [2]. Plants have evolved highly regulated mechanisms that respond to environmental Fe availability and maximise Fe uptake from the soil. Non-graminaceous species primarily use a reduction-based mechanism (traditionally referred to as Strategy I) to convert insoluble ferric $\mathrm{Fe}\left(\mathrm{Fe}^{3+}\right)$ to a more soluble ferrous form $\left(\mathrm{Fe}^{2+}\right)$ for direct plant uptake. In contrast, graminaceous species use a chelation-based mechanism (traditionally referred to as Strategy II) involving the secretion of Fe-chelating phytosiderophores (PSs) that bind $\mathrm{Fe}^{3+}$ for subsequent PS-Fe ${ }^{3+}$ uptake. Despite these differences in Fe acquisition between non-graminaceous and graminaceous plants, both utilise a conserved, complex network of transcription factors (TFs) that respond to environmental Fe conditions and regulate plant Fe uptake, translocation, and homeostasis [3-8].

Master regulators of Fe homeostasis in rice (Oryza sativa L.) include the Fe-binding proteins iron deficiency-responsive element-binding Factor 1 (OsIDEF1), haemerythrin motif-containing really interesting new gene (RING), and zinc finger proteins 1 and 2 (OsHRZ1 and OsHRZ2), which sense environmental Fe concentrations and regulate a 
downstream cascade of TFs [9-11]. The OsHRZ1, OsHRZ2, and BRUTUS (the ortholog of HRZ in Arabidopsis, AtBTS) proteins are RING-type E3 ligases that polyubiquitinate proteins, such as basic helix-loop-helix (bHLH) TFs, for subsequent degradation via the $26 \mathrm{~S}$ proteasome [12]. Targets of OsHRZ ubiquitination activity are likely to include the subgroup IVc bHLH TF positive regulators of iron homeostasis 1, 2, and 3 (OsPRI1/OsbHLH60, OsPRI2/OsbHLH58, and OsPRI3/OsbHLH59 respectively), which in turn positively regulate members of subgroups $\mathrm{Ib}$ and IVb bHLH TFs [13-15]. The subgroup $\mathrm{Ib}$ and IVb TFs include the iron-related transcription factor $2(\mathrm{OsIRO})$ and iron-related transcription factor 3 (OsIRO3) in rice, as well as the OsIRO3 ortholog in Arabidopsis, POPEYE (AtPYE); these form homodimers or heterodimers capable of binding the promoters of Fe-homeostasis genes. While OsIRO2 proteins positively regulate genes involved in the rice Fe deficiency response, the role of OsIRO3 (and AtPYE in Arabidopsis) proteins in the negative regulation of genes involved in Fe uptake and translocation remains poorly understood [16-20].

Bread wheat (Triticum aestivum L.) is produced on more land than any other crop, and provides a fifth of all calories consumed by humans [21]. On alkaline soils, which comprise approximately $30 \%$ of global soils, Fe is less available for plant uptake and can lead to conditions of Fe deficiency [22]. Under Fe deficiency, wheat plants exhibit leaf chlorosis and reduced yield [23]. Recent progress in bread wheat genetics, such as the release of a fully annotated genome sequence and newly integrated databases, has allowed for efficient in silico gene identification [24-28]. The availability of these genetic resources has recently led to a boom in molecular characterisation efforts of wheat genes involved in Fe transport, chelation, and storage; however, there has been little characterisation of upstream regulators of Fe homeostasis to date [29-33]. Genes from diploid (2n) species, such as rice, often have three orthologous sequences (referred to as homoeologs) in the hexaploid (AABBDD $=6 n$ ) bread wheat genome. Characterising all three homoeologs in bread wheat is critical, as approximately $30 \%$ of wheat homoeologs show expression bias towards one subgenome [34,35]. Given the complexity of the bHLH TF family proteins (such as IRO2 and IRO3) and the redundancy of the bread wheat genome, the Fe homeostasis network in bread wheat is likely to be more complicated than in related diploid species. Characterising components of the Fe homeostasis network in bread wheat will shed light on this complexity, and may identify novel resources for improving wheat abiotic stress tolerance under Fe-limiting conditions. Here, we have identified, annotated, and characterised the three TaIRO3, TaHRZ1, and TaHRZ2 homoeologs in bread wheat, which collectively represent key regulatory genes in the Fe homeostasis network.

\section{Materials and Methods}

\subsection{Identification and Validation of TaIRO3 and TaHRZ Genes}

Identification of the TaIRO3, TaHRZ1, and TaHRZ2 genes in bread wheat was performed following the guidelines outline in Bonneau et al. [27]. Briefly, the OsIRO3 (LOC_Os03g26210), OsHRZ1 (LOC_Os01g49470), and OsHRZ2 (LOC_Os05g47780) DNA and protein sequences were used as queries in BLAST searches against the International Wheat Genome Sequencing Consortium (IWGSC) bread wheat reference genome databases (https: / / plants.ensembl.org/ (accessed on 13 April 2020), https:/ / urgi.versailles.inra.fr/ (accessed on 13 April 2020)), and subsequent putative TaIRO3 and TaHRZ sequences were validated against the rice reference genome database (http:/ / rice.plantbiology.msu.edu/ index.shtml (accessed on 13 April 2020)) [36-38]. All putative TaIRO3 and TaHRZ gene sequences and associated splice variants were annotated with "high confidence" by the IWGSC (https:/ / plants.ensembl.org/ (accessed on 13 April 2020)) and validated by a bread wheat expressed sequence tags (ESTs) database (https:/ /blast.ncbi.nlm.nih.gov / (accessed on 17 April 2020)) [25,39]. The TaIRO3 or TaHRZ splice variant that had the highest protein identity to its corresponding homoeologs was considered the main transcript for this study. Naming each TaIRO3 and TaHRZ gene followed the recommended rules for gene symbolization in wheat (http:/ / wheat.pw.usda.gov/ggpages/wgc/98/Intro.htm (accessed on 11 August 2020)) and was based on subgenome and homoeologous grouping. 


\subsection{Phylogenetic Analyses}

Wheat, rice, and Arabidopsis IRO3 and HRZ protein sequences were used as queries in BLAST searches against the brachypodium (Brachypodium distachyon), barley (Hordeum vulgare L.), barrel medic (Medicago truncatula), common bean (Phaseous vulgaris L.), black cottonwood (Populus trichocarpa), tomato (Solanum lycopersicum L.), potato (Solanum tuberosum L.), sorghum (Sorghum bicolor L.), red clover (Trifolium pratense L.), and maize (Zea mays L.) genome databases (https: / / plants.ensembl.org/) to identify putative IRO3 proteins (labelled bHLH047, IRO3, or bHLH063) and HRZ proteins (labelled BTS or HRZ) in a range of eudicot and monocot species [38]. The putative barley HvHRZ2 protein sequence was identified through BLAST searches against the barley reference genome database (https://webblast.ipk-gatersleben.de/barley_ibsc/ (accessed on 19 August 2020)) [40,41]. The putative IRO3 and HRZ proteins were validated against the wheat (https:/ / plants. ensembl.org/ (accessed on 19 August 2020)), rice (http: / / rice.plantbiology.msu.edu/index. shtml (accessed on 19 August 2020)), and Arabidopsis (https://www.arabidopsis.org/ (accessed on 19 August 2020)) reference genome databases prior to phylogenetic analysis $[36,42]$. Sequence alignment of eudicot and monocot IRO3 and HRZ proteins was performed using Geneious software (https:/ /www.geneious.com/v11.0.6 (accessed on 20 August 2020)), and phylogenetic construction was performed using the PhyML Geneious plugin with the LG substitution model and a bootstrap value of 1000 [43]. Conserved protein domains within IRO3 and HRZ proteins were predicted using InterPro EMBL-EBI software (https: / / www.ebi.ac.uk/interpro/ (accessed on 27 August 2020)) [44]. The IRO3 and HRZ proteins used in sequence alignment and phylogenetic analysis are provided in Table S2.

\subsection{Bread Wheat Tissue Sampling and Quantitative Reverse Transcription-PCR (qRT-PCR) Analyses of the TaIRO3 and TaHRZ Genes}

To assess tissue-specific expression of the TaIRO3 and TaHRZ genes in the bread wheat cultivar (cv.) Chinese Spring, a catalogue of cDNA from ten different tissues at various developmental stages was generated, as described by Schreiber et al. [45]. Briefly, total RNA was extracted from tissues harvested from 7-10 plants to produce three independent biological samples of cDNA. The tissues analysed in this study included embryonic root and mesocotyl (two-day-old embryos); seedling root, crown, and seedling leaves collected 10-12 days after sowing; bracts, anthers, and pistils (prior to anthesis); and caryopsis and embryos collected $3-5$ and 22 days after pollination (DAP), respectively.

To determine how TaIRO3 and TaHRZ gene expression is influenced by environmental Fe conditions, total RNA was extracted and cDNA generated from bread wheat cv. Gladius shoot and root tissues, as described in Bonneau et al. [30]. Briefly, wheat seedlings were grown in $20 \mathrm{~L}$ tubs containing a nutrient-replete, hydroponic growth solution for three weeks before transfer to an Fe deficiency treatment for one week. During the Fe deficiency treatment period, wheat plants were subjected to either Fe sufficient $(50 \mu \mathrm{M})$ or Fe deficient $(0 \mu \mathrm{M})$ conditions, with shoot and root tissues harvested from three individual wheat plants at days $0,1,5$, and 7 of the treatment period.

Quantitative reverse-transcription PCR (qRT-PCR) analyses of the three TaIRO3, TaHRZ1, and TaHRZ2 genes in the tissues of bread wheat cultivars Chinese Spring and Gladius were carried out using subgenome-specific primers (Table S3) that were validated using Chinese Spring nulli-tetrasomic DNA [46]. Relative expression for each TaIRO3 and TaHRZ gene was calculated based on a standard curve of triplicate, 10-fold serial dilutions $\left(10^{1}-10^{7}\right)$ of purified template for each primer pair, and were based on the amount of RNA ( $\mu \mathrm{g})$ included in the reaction. A three-gene normalisation factor (3GNF) of the wheat house-keeping genes-cyclophilin (TaCyc), actin (TaActin), and elongation factor 1- $\alpha$ (TaEFA) for $\mathrm{cv}$. Chinese Spring, and TaCyc, TaActin, and glyceraldehyde 3-phosphate dehydrogenase $(T a G A P D H)$ for cv. Gladius-was used to normalise TaIRO3 and TaHRZ qRT-PCR gene expression data [47]. Expression data for TaIRO3 and TaHRZ genes was normalised independently for shoot and root tissues in cv. Gladius. The relative expression level of each 
TaIRO3, TaHRZ1, and TaHRZ2 homoeolog was compared between subgenomes, using the ternary plot function in the Wheat Expression Browser database (wheat-expression.com (accessed on 1 April 2021)) [35,48] (Figure S1).

\subsection{Gene Network Construction}

A TaIRO3, TaHRZ1 and TaHRZ2 gene network was generated using the bread wheat database of KnetMiner software (https:// knetminer.org/\$ upbeta\$/Triticum_aestivum/ (accessed on 4 September 2020)), which compiles a network of bread wheat genes and related orthologs from Arabidopsis and rice. Regulatory associations between bread wheat transcription factors and our queries were predicted by Genie3 software, which was recently integrated into KnetMiner [49]. A complete network containing all the phenotypic traits and molecular functions associated with the TaIRO3 homoeologs and TaHRZ gene family is available at https:// knetminer.com/\$ $\backslash$ upbeta $/$ knetspace/network/f6c84de2-9 2ae-45e3-a068-0e61419b24cb, and all bread wheat gene identification numbers are provided in Supplementary Table S1.

\subsection{Statistical Analysis}

Statistically significant differences in cv. Gladius tissue gene expression under Fe-sufficient or Fe-deficient conditions was determined at each time point of the treatment period using a two-sample Student's $t$-test (assuming equal variances) in Minitab software (http:/ / www. minitab.com/en-us/v19.0 (accessed on 28 April 2020)). Graphs were generated using the ggplot2 package in RStudio (https: / /rstudio.com/v3.6.3 (accessed on 28 April 2020)).

\section{Results}

3.1. Three TaIRO3 Genes Are Located on Chromosomal Group 2, and Six TaHRZ Genes Are Located on Chromosomal Groups 1 and 3

Three TaIRO3 homoeologous genes were identified on chromosomal group 2 of the bread wheat genome, with one TaIRO3 homoeolog located on each of the A, B, and D subgenomes (hereafter referred to as TaIRO3- $A$, TaIRO3- $B$, and TaIRO3-D, respectively). The TaIRO3 genomic sequences ranged between 2379 to 2679 base pairs (bp), due to differences in intron length (Figure 1). Gene structure was conserved across the TaIRO3 homoeologs, except for TaIRO3-B, which possesses a truncated coding region and an intron within its $5^{\prime}$ UTR. Genomic sequence identity within the TaIRO3 homoeologs was between $76.9 \%$ to $79.8 \%$. Three TaHRZ1 genes were identified on chromosomal group 3 , and three TaHRZ2 genes were identified on chromosomal group 1 of the bread wheat genome. One TaHRZ1 and one TaHRZ2 homoeolog were identified on each of the A, B, and D sub-genomes (hereafter referred to as TaHRZ1- $A$, TaHRZ1-B, TaHRZ1-D, TaHRZ2-A, TaHRZ2-B, and TaHRZ2-D, respectively). The TaHRZ1 genomic sequences ranged between 11,406 to $12,345 \mathrm{bp}$, and the TaHRZ2 genomic sequences ranged between 9116 to $9585 \mathrm{bp}$, due to differences in intron length (Figure 2). Gene structure was conserved among the TaHRZ gene family, with genomic sequence identity ranging between $88.9 \%$ to $95.9 \%$ for the TaHRZ1 homoeologs and $83.3 \%$ to $93.1 \%$ for the TaHRZ2 homoeologs. In addition to the six TaHRZ genes, we identified 36 predicted splice variants within the TaHRZ gene family (Table S1). 


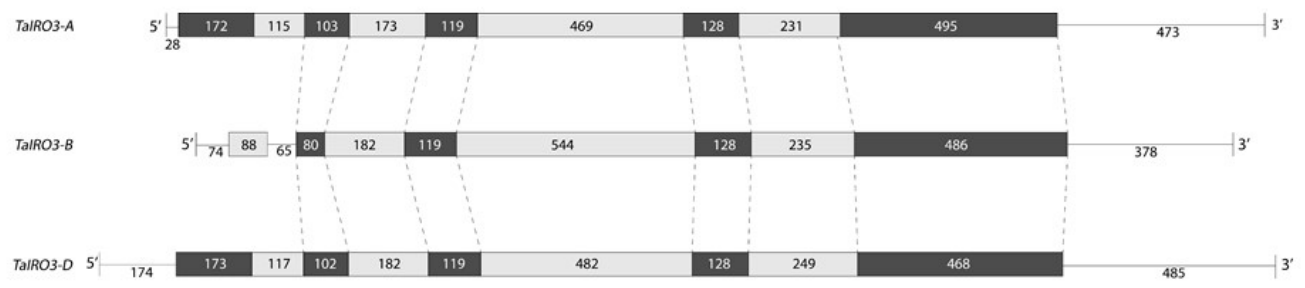

Figure 1. Gene structure of the TaIRO3 homoeologs in bread wheat cv. Chinese Spring. Coding sequences (black boxes), introns (grey boxes), and known untranslated regions (lines) of TaIRO3 homoeologs are depicted with length (base pairs) provided.

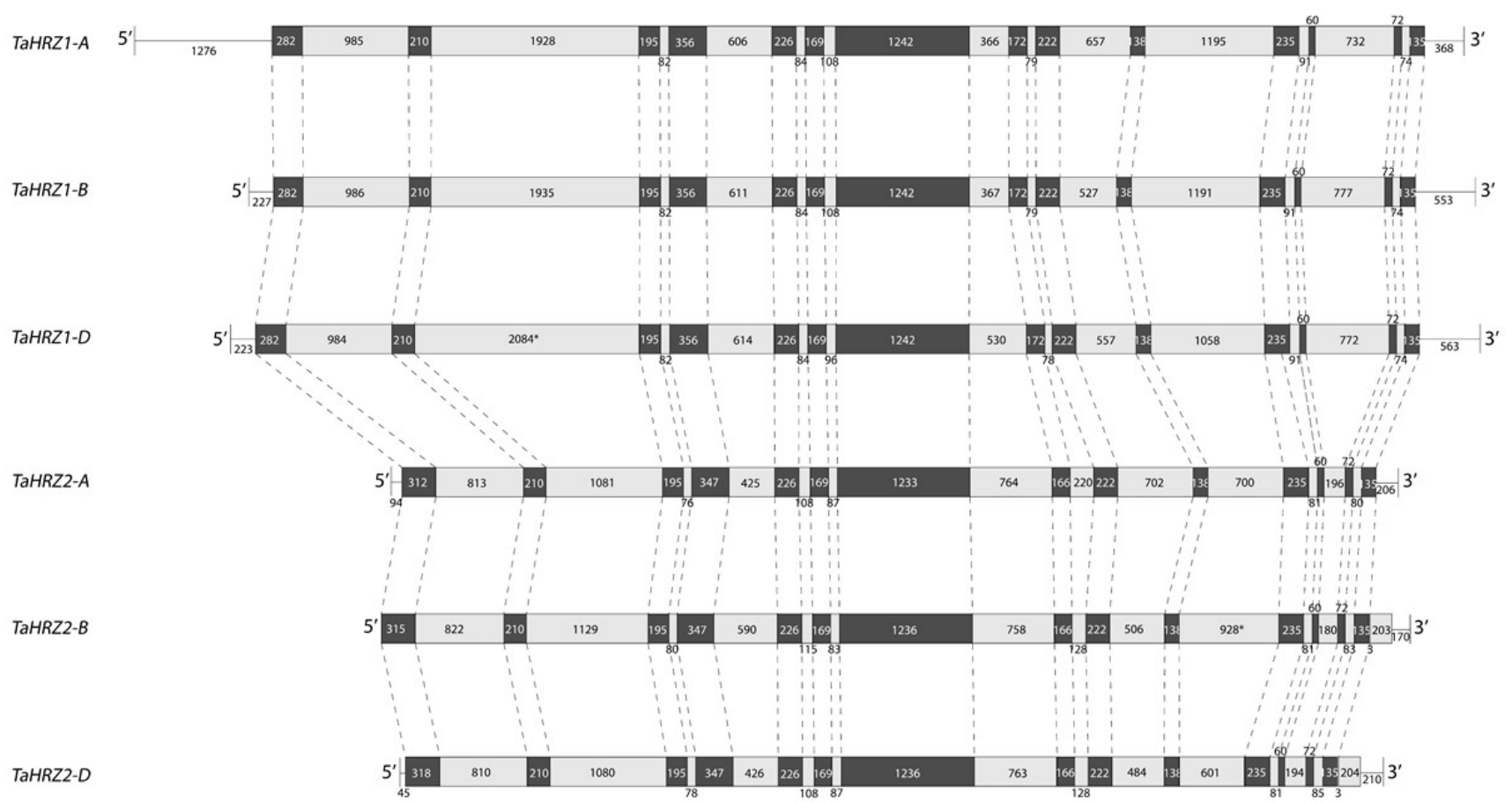

Figure 2. Gene structure of the TaHRZ1 and TaHRZ2 homoeologs in bread wheat cv. Chinese Spring. Coding sequences (black boxes), introns (grey boxes), and known untranslated regions (lines) of TaHRZ1 and TaHRZ2 homoeologs are depicted with lengths (base pairs) provided. Asterisk indicates introns of estimated length.

\subsection{IRO3 Proteins Are Conserved within Graminoids and Separate between Monocots and Eudicots}

Phylogenetic analysis of IRO3 proteins from a range of monocots (referred to as IRO3 or bHLH063) and eudicots (referred to as PYE or bHLH047) identified two groups of IRO3 proteins (Figure 3). The TaIRO3 proteins were most closely related to the barley IRO3 (HvIRO3) protein, ranging between 271 to 339 amino acids (aa) in length and shared between $74.5 \%$ to $90.8 \%$ identity (Figure 3a,b). All IRO3 proteins contained the highly conserved HLH domain of bHLH-type TFs, which functions in protein dimerisation and DNA binding (Figure S2). A conserved, ethylene-responsive, element binding factorassociated amphiphilic repression (EAR) or "EAR-like" motif was identified in both eudicot (DLNxxP or VLNxxP) and monocot (LxLxL or RxLxL) IRO3 proteins. 
a Eudicots

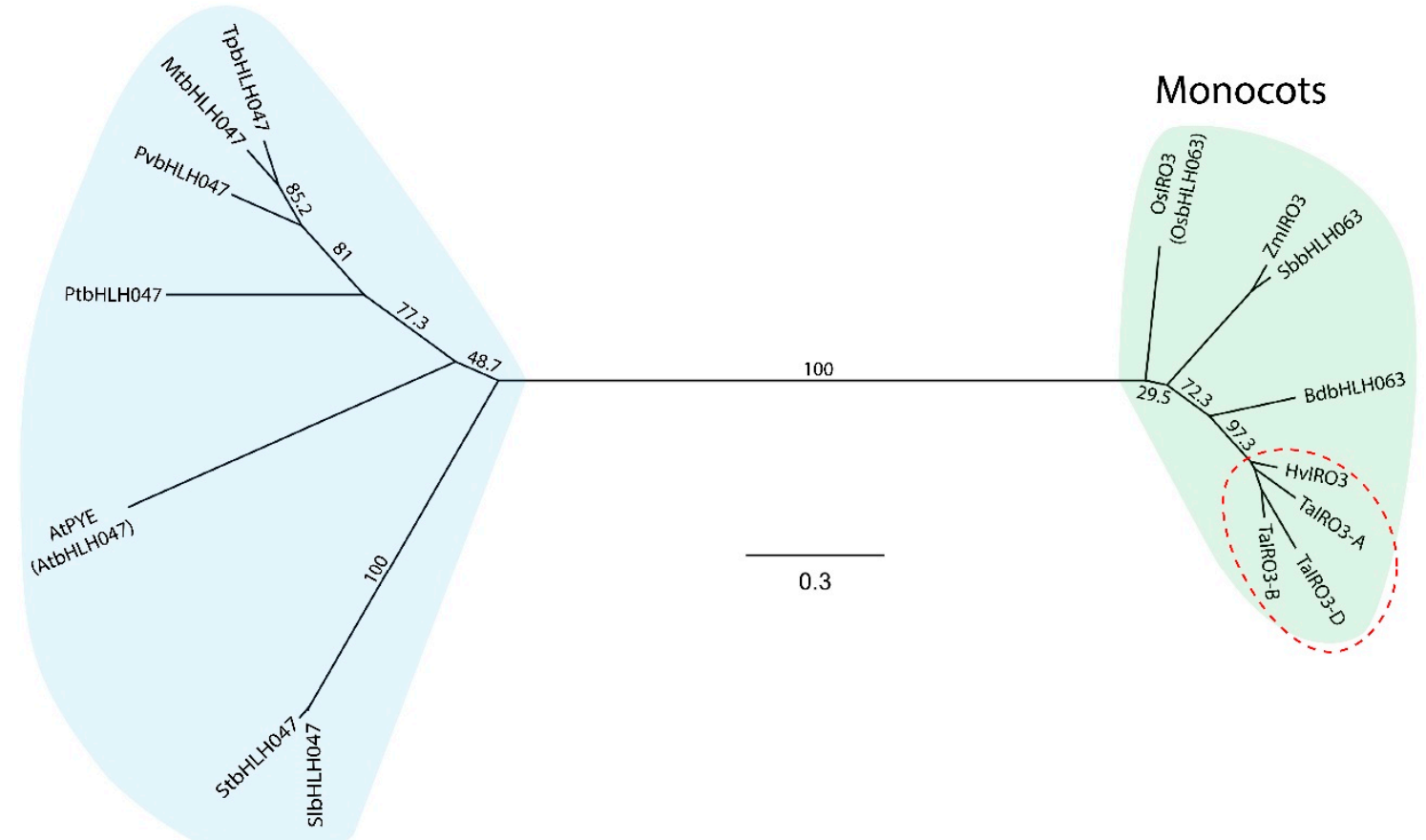

b

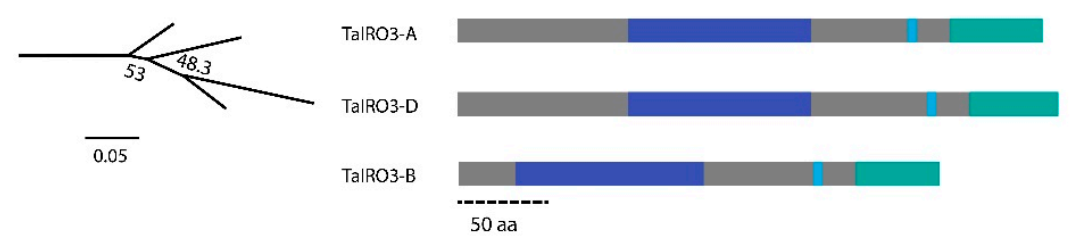

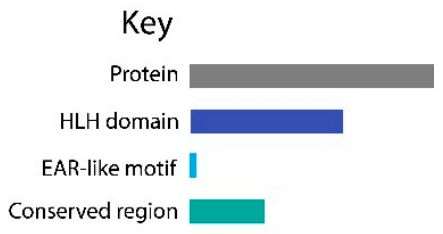

Conserved region

Figure 3. Phylogenetic comparison of IRO3 proteins in higher plants. (a) An unrooted phylogenetic tree of IRO3/PYE proteins, showing eudicot and monocot groups (light blue), as well as a graminiod subgroup (green). The red circle indicates the IRO3 proteins in Triticeae. (b) The structure of TaIRO3 proteins with conserved domains highlighted. The region in green labelled "Conserved region" has an unknown function. Dashed scale bar indicates length in amino acids. Numbers indicate bootstrap percentage, and scale bars represent evolutionary distance in substitutions per site. Abbreviations: Arabidopsis thaliana (At), Brachypodium distachyon (Bd), Hordeum vulgare L. (Hv), Medicago truncatula (Mt), Oryza sativa L. (Os), Phaseolus vulgaris L. (Pv), Populus trichocarpa (Pt), Solanum lycopersicum L. (Sl), Solanum tuberosum L. (St), Sorghum bicolor L. (Sb), Trifolium pratense L. (Tp), Triticum aestivum L. (Ta), and Zea mays L. (Zm).

\subsection{HRZ Proteins Are Highly Conserved and Separate into Two Clades in Graminaceous Species}

Phylogenetic analysis of HRZ proteins from a range of monocots and eudicots (referred to as BTS) identified two groups of HRZ proteins (Figure 4). The graminaceous species within monocots further separates into two clades, with the TaHRZ1 proteins forming one clade with HvHRZ1, BdHRZ1, OsHRZ1, SbHRZ1, and ZmHRZ1, and the TaHRZ2 proteins forming a second clade with HvHRZ2, BdHRZ2, OsHRZ2, SbHRZ2, and ZmHRZ2 (Figure 4a). The TaHRZ1 proteins were all 1237 aa in length and shared between $97.8 \%$ to 99.1\% identity, and the TaHRZ2 proteins ranged between 1239 to 1242 aa in length and shared between $95.5 \%$ to $98.1 \%$ identity (Figure $4 \mathrm{~b}$ ). All HRZ proteins contained at least one hemerythrin domain, with the TaHRZ proteins containing three hemerythrin domains each. All HRZ proteins contained a conserved zinc (Zn)-finger region (comprised of CHY-type, CTCHY-type, and RING-type motifs), and all HRZ proteins (except for SbHRZ1) contained a RCHY1 Zn-ribbon domain near the C-terminus (Figure S3). 


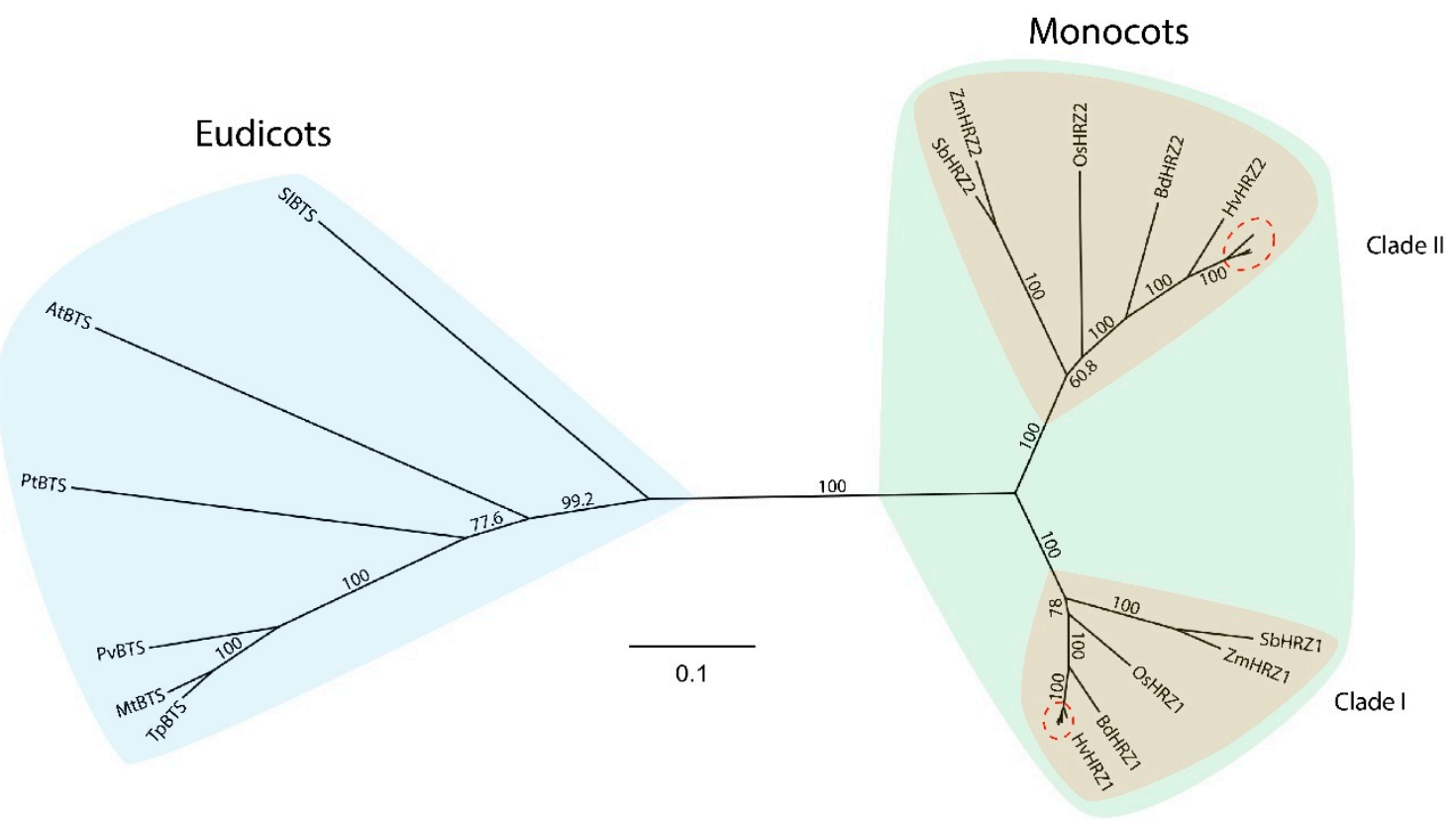

b
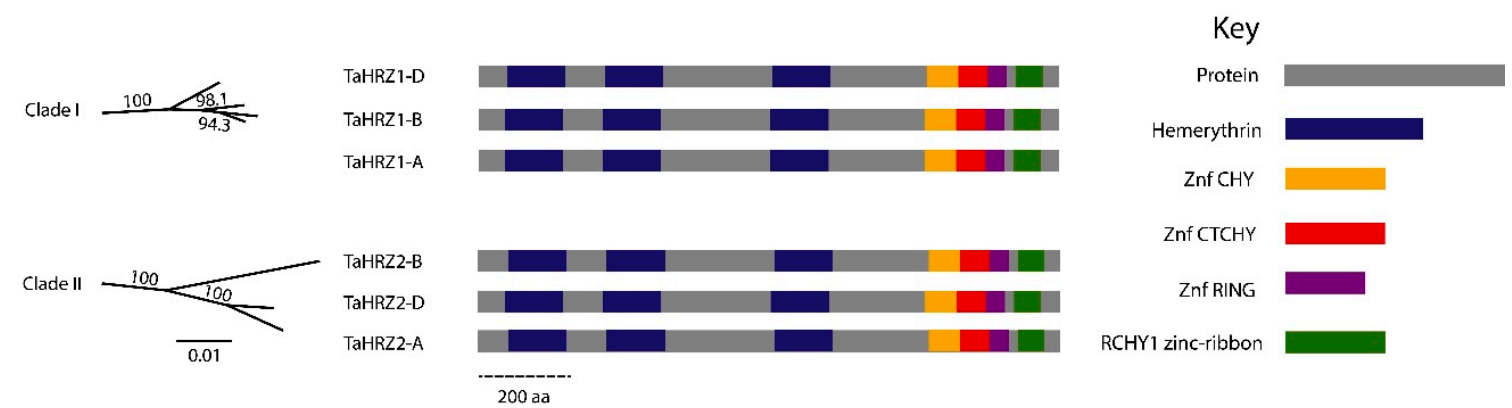

Figure 4. Phylogenetic comparison of HRZ1 and HRZ2 proteins in higher plants. (a) An unrooted phylogenetic tree of HRZ1 and HRZ2 proteins, showing eudicot (light blue) and graminiod (green) groups, and the two clades within graminoids (light brown). Red circles indicate the HRZ1 proteins in Triticeae and the TaHRZ2 proteins in wheat. (b) The structure of TaHRZ1 and TaHRZ2 proteins with conserved domains is highlighted. Dashed scale bar indicates length in amino acids. Numbers indicate wheat bootstrap percentage, and scale bars represent evolutionary distance in substitutions per site. Abbreviation: A. thaliana (At), B. distachyon (Bd), H. vulgare L. (Hv), M. truncatula (Mt), O. sativa L. (Os), P. vulgaris L. (Pv), P. trichocarpa (Pt), S. lycopersicum L. (Sl), S. bicolor L. (Sb), T. pratense L. (Tp), T. aestivum L. (Ta), and Z. mays L. (Zm).

3.4. The TaIRO3, TaHRZ1, and TaHRZ2 Homoeologs Have Distinct Expression Patterns in Bread Wheat Tissues and Are Upregulated in Response to Fe Deficiency

Gene expression analysis of the TaIRO3, TaHRZ1, and TaHRZ2 genes across a range of bread wheat cv. Chinese Spring tissues and developmental stages revealed distinct expression patterns (Figure 5). The TaIRO3 genes were broadly expressed across a range of tissues, with the TaIRO3- $A$ homoeolog being expressed higher in the anthers (2.6- to 3.0-fold), caryopsis (23- to 24-fold), and embryo (10- to 13-fold) relative to the TaIRO3-B and TaIRO3-D homoeologs (Figure 5a). The TaHRZ gene family was highly expressed in leaves, bracts, and anthers relative to other tissues, with the expression of TaHRZ1$A$ between 1.5- and 4.0-fold higher than TaHRZ1-B and TaHRZ1-D, and the expression of TaHRZ2-D between 1.4- and 4.8-fold higher than TaHRZ2- $A$ and TaHRZ2-B across all tissues (Figure $5 b, c)$. Similar patterns of relative expression between TaIRO3, TaHRZ1, and TaHRZ2 homoeologs was observed in the Wheat Expression Browser database (Figure S1). Expression of the TaIRO3- $A$ homoeolog was significantly upregulated in bread wheat $\mathrm{cv}$. Gladius shoot tissues at day 1, 5, and 7, and expression of the TaIRO3-B, and TaIRO3$D$ homoeologs was significantly upregulated in shoot tissues at day 5 and 7 of the $\mathrm{Fe}$ 
deficiency treatment (Figure 6). Within the Fe deficiency treatment, expression of the TaIRO3 genes in shoot tissues was upregulated (between 2.0- and 2.9-fold) from day 1 to day 7. In root tissues, the expression of TaIRO3- $B$ was significantly upregulated at day 5 , and expression of TaIRO3- $A$ and TaIRO3- $D$ was significantly upregulated at day 7 of the Fe deficiency treatment (Figure 6). Expression of the TaHRZ genes (except for TaHRZ1-D) was significantly upregulated in shoot tissues at day 1 , and expression of the TaHRZ2-B homoeolog was significantly upregulated in shoot tissues at day 7 of the Fe deficiency treatment (Figure 6). Within the Fe deficiency treatment, expression the TaHRZ genes was downregulated (between 1.5- to 3.2-fold) from day 1 to day 7. In root tissues, expression of TaHRZ1-A, TaHRZ2- $A$, and TaHRZ2-D was significantly upregulated at day five of the Fe deficiency treatment (Figure 6).
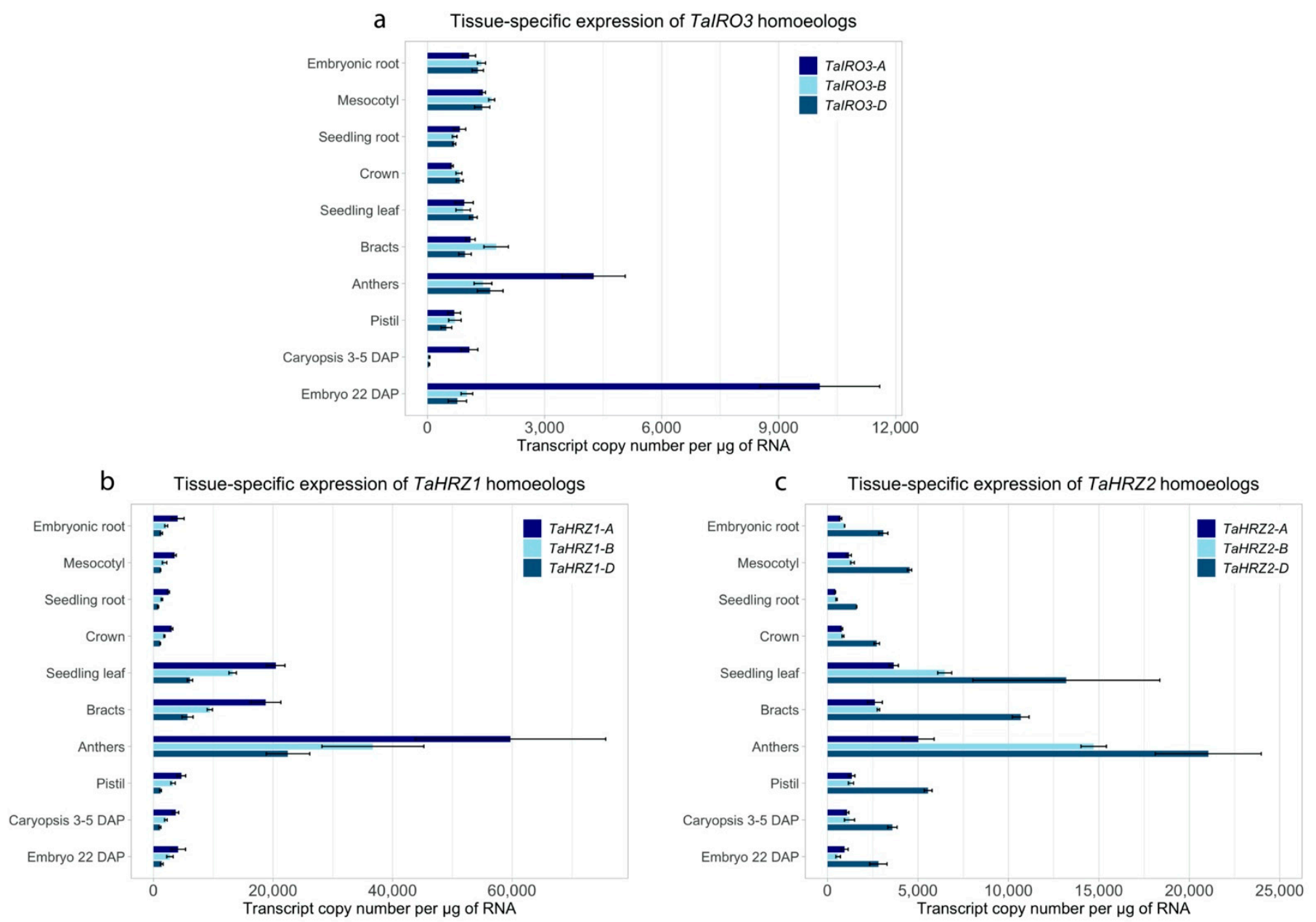

Figure 5. Quantitative reverse-transcription PCR analysis of TaIRO3, TaHRZ1, and TaHRZ2 homoeologs within 10 different tissues and developmental stages of bread wheat cv. Chinese Spring. The relative expression (transcript copy number per $\mu \mathrm{g}$ of RNA) is provided for each homoeolog of (a) TaIRO3, (b) TaHRZ1, and (c) TaHRZ2. Error bars indicate standard deviation of the mean of three technical replicates derived from a bulk of 7-10 independent samples. 

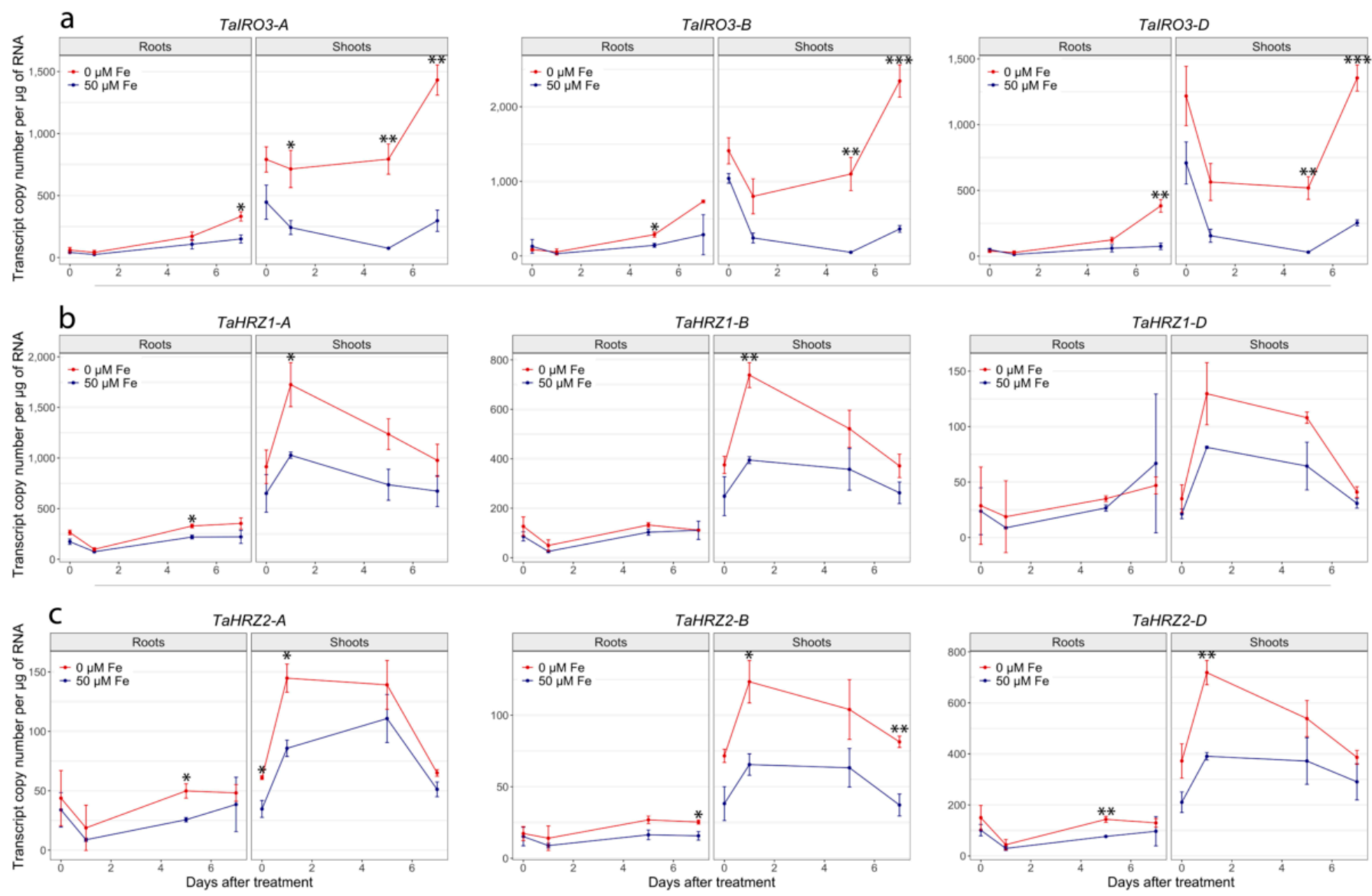

Figure 6. Quantitative reverse-transcription PCR analysis of TaIRO3, TaHRZ1, and TaHRZ2 homoeologs within shoot and root tissues of bread wheat cv. Gladius under Fe sufficient or deficient conditions. The relative expression (transcript copy number per $\mu \mathrm{g}$ of RNA) is provided for each homoeolog of (a) TaIRO3, (b) TaHRZ1, and (c) TaHRZ2 in root and shoot tissues. Timepoints correspond to 0 (experiment start), 1, 5, or 7 days of growth under Fe sufficient (+Fe, blue line) or Fe deficient $(-\mathrm{Fe}$, red line) conditions. Error bars indicate the SEM of three biological replicates of each homoeolog $(n=3)$. Asterisks indicate significant differences between Fe deficient and sufficient conditions at each time point (two-sample Student's $t$-test assuming equal variance; ${ }^{*}=p$ value $\leq 0.05 ;{ }^{* *}=p$ value $\leq 0.01 ;{ }^{* * *}=p$ value $\left.\leq 0.001\right)$.

\subsection{The TaIRO3 and TaHRZ Genes Are Associated with Regulatory Components of Fe Homeostasis in Arabidopsis and Rice}

KnetMiner analysis of the TaIRO3 and TaHRZ gene sequences confirmed the presence of three TaIRO3, three TaHRZ1, and three TaHRZ2 homoeologs in the bread wheat genome. A KnetMiner network revealed regulatory associations between predicted TaIRO3 proteins and OsbHLH062 in rice (a subgroup IVb TF), as well as regulatory associations between predicted TaHRZ proteins and AtBTS (Figure 7). The predicted TaHRZ proteins were also associated with the rice stress-related ring finger protein 1 (OsSRFP1). The network showed physical interactions between AtBTS and the subgroup IVc TFs AtbHLH115, AtILR3 and AtbHLH104. Genie3 software uncovered putative TFs belonging to subgroup Ib, ABI3/VP1 (TaABI3), and other putative TFs (TaARF1) predicted to have regulatory associations with TaHRZ and TaIRO3 genes. 


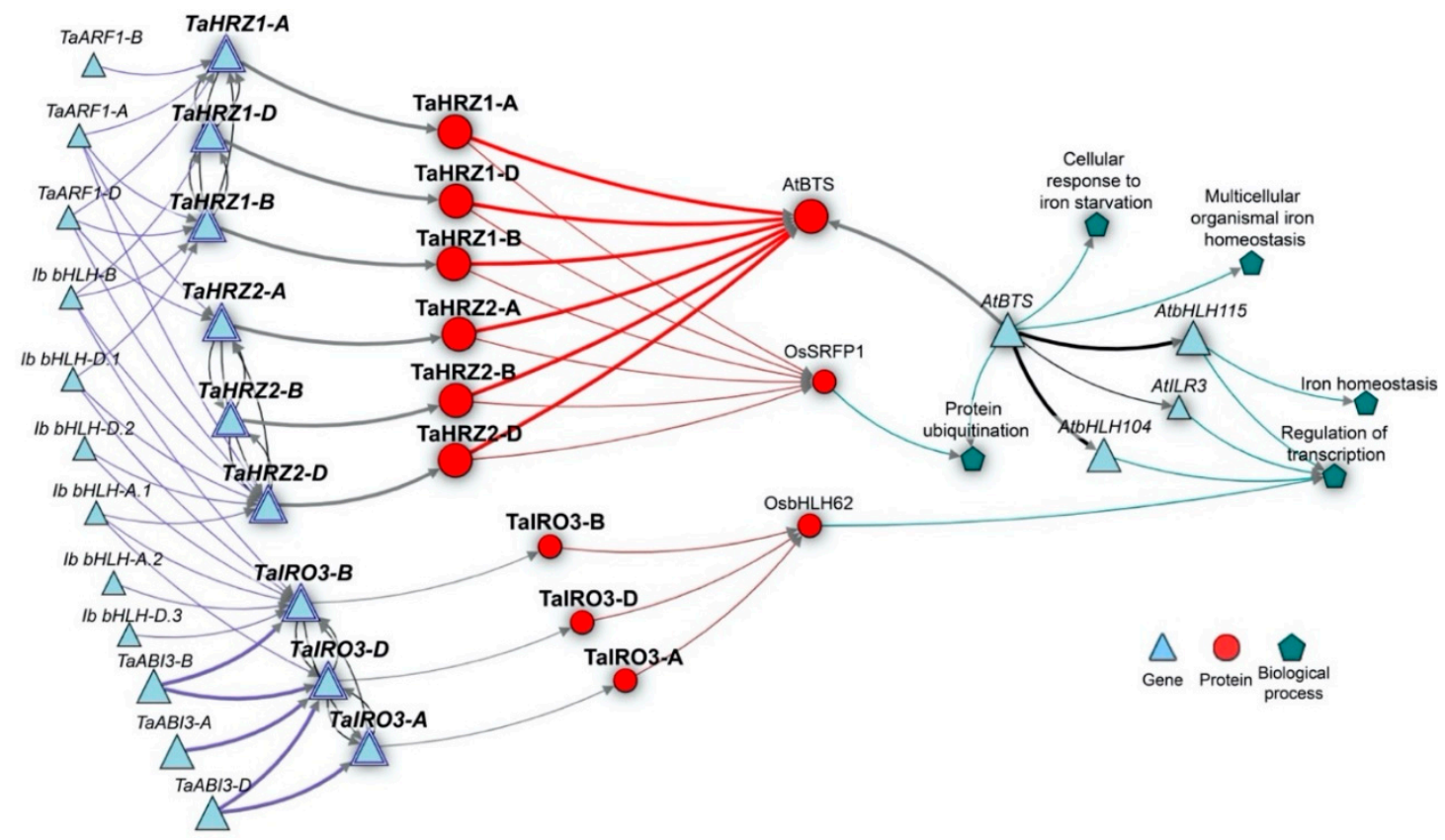

Figure 7. Condensed Knetminer gene network of TaIRO3, TaHRZ1 and TaHRZ2 homoeologs. Novel transcription factor associations are predicted with Genie3. Blue lines represent regulatory associations. Thick blue lines represent associations between ABI3/VP1 transcription factor family and the TaIRO3 homoeologs. Transcription factors with fewer than two links were excluded. Grey lines represent a gene encoding a protein. Red lines indicate a similar protein sequence. Teal lines represent a role in a biological process. Black lines indicate physical interactions. Lines between TaHRZ and TaIRO3 gene families represents homoeologous relationship.

\section{Discussion}

Understanding how $\mathrm{Fe}$ is regulated in wheat and other staple crops is essential for maximising crop production under Fe-limiting, alkaline soil conditions. Identifying regulatory components of Fe homeostasis in wheat was difficult until the recent release of a fully annotated bread wheat genome and integrated databases [24-26]. Here, we identified, annotated, and characterised the TaIRO3, TaHRZ1 and TaHRZ2 genes in bread wheat, which together act to regulate Fe homeostasis transcriptionally and post-transcriptionally. The TaIRO3 proteins belong to the subgroup IVb bHLH TF family, one of 26 subgroups that are composed of more than $147 \mathrm{bHLH}$ TFs in plants, and regulate transcription by dimerising and binding E-boxes (CANNTG) in gene promoters via a basic region of the HLH domain (Figure 3b) [50-52]. Once bound to DNA, IRO3 proteins are thought to repress transcription by recruiting a histone deacetylating complex via an ethylene-responsive, element binding factor-associated, amphiphilic repression (EAR) motif [53]. The EAR motif commonly has consensus sequence DLNxxP or LxLxL, and here we observed conservation of the DLNxxP motif at amino acid position 221 in eudicots (Figure S2). In contrast, the EAR motif in monocot IRO3 proteins was conserved at amino acid position 286, and had the sequence LxLxL (in ZmIRO3, SbbHLH063 and OsIRO3 proteins) or RxLxL (all other monocots, including the TaIRO3 proteins). A subgroup IVb bHLH TF in Arabidopsis, AtbHLH11, was also recently described to have a functional LxLxL EAR motif near amino acid position 286 [54]. Given that RxLxL is an atypical EAR motif sequence, we have labelled this sequence as "EAR-like" in the TaIRO3 proteins, and further research is required to confirm whether this motif is functional in bread wheat. In contrast to the TaIRO3 proteins, the TaHRZ proteins belong to an E3-ligase family that contain conserved, putative metal-binding domains (hemerythrin, CHY-type, CTCHY-type, RING-type, and RCHY1 Zn-ribbon) that together act to post-transcriptionally regulate genes [10,55]. All HRZ proteins contained a conserved $\mathrm{Zn}$-finger region (containing CHY-type, CTCHY-type, and RING-type motifs) at the C-terminus that is responsible for polyubiquitination and the 
subsequent degradation of proteins (Figure $4 \mathrm{~b}$ ). In addition to the $\mathrm{Zn}$-finger region, all HRZ proteins (except for SbHRZ1) contain a conserved RCHY1 Zn-ribbon domain (also known as a rubredoxin-type fold), and investigating whether there is variation in posttranscriptional regulation between S. bicolor (which lacks the RCHY1 Zn-ribbon domain) and other monocots is warranted (Figure S3). All HRZ proteins also contain at least one hemerythrin domain, with TaHRZ proteins containing three hemerythrin domains, which bind to $\mathrm{Fe}, \mathrm{Zn}$, and/or oxygen atoms, resulting in changes to protein stability [11,56]. The eudicot BTS-like (BTSL) family of proteins contain only two hemerythrin domains and perform a separate role to BTS in Fe homeostasis, suggesting that the hemerythrin domains may be important in the regulation of Fe homeostasis, although this requires further investigation [57]. We identified several splice variants of the TaHRZ1 genes that encode proteins with a reduced number of hemerythrin domains or missing motifs within the $\mathrm{Zn}$-finger region (Table S1). As alternative gene splicing plays a key role in response to Fe stress in Arabidopsis and rice, these TaHRZ splice variants may be critical to maintaining Fe homeostasis in wheat [58-60]. Furthermore, the truncated TaHRZ proteins encoded by these splice variants provide a novel resource for confirming the role of hemerythrin domains and the $\mathrm{Zn}$-finger region within the TaHRZ proteins.

The TaIRO3, TaHRZ1, and TaHRZ2 genes share patterns of gene expression in bread wheat tissues that suggest they are part of the same Fe homeostasis regulatory network. We detected high expression of the TaHRZ genes and the TaIRO3- $A$ homoeolog in wheat anther tissues (Figure 5), which contain high levels of Fe and $\mathrm{Zn}$ that are essential for pollen germination [61]. Genes involved in the biosynthesis of the Fe chelators nicotianamine (NA) and 2'deoxymugineic acid (DMA) are also highly expressed in bread wheat anthers, suggesting that the high concentrations of anther Fe requires tight regulation in order to avoid oxidative stress and tissue damage [29,30]. Interestingly, high expression of the TaIRO3- $A$ homoeolog (relative to TaIRO3-B and TaIRO3-D) in the developing wheat embryo (Figure 5a) suggests that homoeologous wheat genes may perform tissue-specific functions, and similarly, high levels of TaIRO3 expression in the wheat grain were observed in a USDA wheat expression database (https:/ / wheat.pw.usda.gov/WheatExp/ (accessed on 28 April 2020)) [62,63]. The TaHRZ gene family was highly expressed in shoot tissues throughout the wheat lifecycle (Figures 5 and 6), suggesting that TaHRZ proteins regulate Fe homeostasis more in wheat leaf tissues relative to wheat root tissues; a similar shoot-specific function for OsHRZ proteins has been hypothesised in rice [10]. The OsHRZ proteins in rice root tissues are degraded, and may therefore result in the upregulated expression of genes related to Fe uptake and translocation (i.e., NA synthase, NA aminotransferase, etc.) in rice roots. Under conditions of Fe deficiency, all TaIRO3 and TaHRZ genes were upregulated in shoot tissues (Figure 6), although at different timepoints. All members of the TaHRZ gene family (except for TaHRZ1-D) were upregulated in wheat shoot tissues within $24 \mathrm{~h}$ of exposure to the Fe deficiency treatment, whereas upregulation of the TaIRO3 genes in shoot tissues did not occur until day 5 of Fe deficiency (Figure 6). Together, these results provide evidence that TaHRZ acts upstream of TaIRO3 in the wheat Fe deficiency response, which is supported by gene expression and biochemical evidence that OsHRZ regulates OsIRO3 in the rice Fe deficiency response $[10,13,18]$. The expression of all TaHRZ genes in wheat shoot tissues was downregulated after $24 \mathrm{~h}$ of Fe deficiency, whereas the expression of OsHRZ in rice shoot tissues is upregulated up to day 7 of Fe deficiency [10]. Together, these results point to key differences in the regulation of Fe homeostasis between rice and wheat, and suggest that TaHRZ genes may form a negative feedback loop in wheat shoot tissues. We propose the TaHRZ proteins in wheat are pivotal for managing Fe homeostasis, and that downregulation of the TaHRZ genes after $24 \mathrm{~h}$ of Fe deficiency allows for upregulation of Fe deficiency response genes (including TaIRO3 and NA/DMA biosynthesis genes), to ensure wheat plants can absorb sufficient Fe for growth [29-31]. Our KnetMiner/Genie 3 network confirms that all TaHRZ and TaIRO3 genes are distinct homoeologs present in the bread wheat genome and identifies regulatory associations predicted from gene expression data between the TaHRZ and TaIRO3 
genes, with five genes belonging to the subgroup $\mathrm{Ib}$ bHLH TF family (including a putative OsIRO2 ortholog) and three genes belonging to the ABI3/VP1 TF family in bread wheat (Figure 7) [35,49]. These ABI3/VP1 genes could be related to the master Fe sensor OsIDEF1 in rice, and future analysis will aim to characterise these novel TFs in bread wheat and determine whether the TaABI3/VP1 genes share similar Fe sensing roles to OsIDEF1 [64]. The KnetMiner network includes a different rice bHLH protein to OsIRO3, OsbHLH062, likely due to incomplete incorporation of the rice genome database into KnetMiner. We anticipate that the OsbHLH062 gene encodes a closely related TF to OsIRO3 in rice, and therefore warrants further investigation in future rice Fe homeostasis studies. The Genie3 software did not identify any subgroup IVc bHLH TFs in our KnetMiner network, likely due to Genie3 using RNA-seq datasets, and that IVc bHLH TFs (including OsPRI1/2/3) are not regulated at the transcriptional level [13-15].

Loss- and gain-of-function studies in rice and Arabidopsis have demonstrated that $\mathrm{HRZ}$ and IRO3 proteins repress the Fe deficiency response, and suggest that similar approaches coupled with in planta protein analyses are now required to confirm TaHRZ and TaIRO3 function in bread wheat [10,17-20]. No knockdowns of OsIRO3 or AtPYE have been reported to date; however, a knockout of OSIRO3 in rice upregulated the expression of Fe deficiency response genes in rice roots under Fe sufficiency, and resulted in Fe toxicity in shoot tissues under Fe deficiency $[19,20]$. Knockout of AtBTS in Arabidopsis is embryonically lethal; however, knockdowns of AtBTS and OsHRZ in Arabidopsis and rice, respectively, have enhanced Fe deficiency tolerance and increased grain Fe concentration $[10,65]$. Knocking out individual TaIRO3/TaHRZ homoeologs within the bread wheat genome may be less detrimental than in diploid species, due to genetic redundancy in the hexaploid genome, and may instead mimic the effect of knocking down OsIRO3/AtPYE or OsHRZ/AtBTS genes in rice and Arabidopsis. The TaIRO3 and TaHRZ genes identified in this study contribute to our understanding of Fe homeostasis in bread wheat, and provide a novel resource for marker-assisted selection, genome editing, and genetic modification of bread wheat to improve abiotic stress tolerance and increase grain Fe concentration.

Supplementary Materials: The following are available online at https:/ / www.mdpi.com/article / 10.3390/genes12050653/s1, Supplementary Figure S1: Ternary plots showing expression levels of TaIRO3, TaHRZ1, and TaHRZ2 genes. Supplementary Figure S2: Conserved amino acid sequences of IRO3/PYE proteins. Supplementary Figure S3: Conserved amino acid sequences of HRZ1 and HRZ2 proteins. Supplementary Table S1: Characteristics of TaIRO3 and TaHRZ genes and in silico characterisation of TaIRO3 and TaHRZ proteins. Supplementary Table S2: The orthologous IRO3/bHLH063/bHLH047/PYE and HRZ/BTS proteins included in phylogenetic analyses. Supplementary Table S3: Primers used for quantitative reverse-transcription PCR analyses.

Author Contributions: Conceptualization, O.C.-F. and J.T.B.; methodology, O.C.-F., J.T.B., and A.A.T.J.; software, O.C.-F.; validation, O.C.-F. and J.T.B.; formal analysis, O.C.-F.; investigation, O.C.-F. and J.T.B.; resources, A.A.T.J.; data curation, O.C.-F.; writing-original draft preparation, O.C.-F. and J.T.B.; writing-review and editing, O.C.-F., J.T.B., and A.A.T.J.; visualization, O.C.-F.; supervision, A.A.T.J.; project administration, A.A.T.J.; funding acquisition, A.A.T.J. All authors have read and agreed to the published version of the manuscript.

Funding: This research was supported by grants from the Australian Research Council (LP190100631) and HarvestPlus.

Institutional Review Board Statement: Not applicable.

Informed Consent Statement: Not applicable.

Data Availability Statement: The data presented in this study are openly available in FigShare at https:/ / doi.org/10.26188/14483346.v1.

Acknowledgments: The authors would like to thank Julien Bonneau for assistance with plant growth and preliminary genomic analyses, and Yuan Li for technical assistance in qRT-PCR analyses.

Conflicts of Interest: The authors declare no conflict of interest. 


\section{References}

1. Kroh, G.E.; Pilon, M. Regulation of Iron Homeostasis and Use in Chloroplasts. Int. J. Mol. Sci. 2020, 21, 3395. [CrossRef]

2. Ravet, K.; Pilon, M. Copper and Iron Homeostasis in Plants: The Challenges of Oxidative Stress. Antioxid. Redox Signal. 2013, 19, 919-932. [CrossRef]

3. Kobayashi, T.; Nishizawa, N.K. Iron Uptake, Translocation, and Regulation in Higher Plants. Annu. Rev. Plant Biol. 2012, 63, 131-152. [CrossRef]

4. Connorton, J.M.; Balk, J.; Rodríguez-Celma, J. Iron homeostasis in plants-A brief overview. Metallomics 2017, 9, 813-823. [CrossRef]

5. Kobayashi, T.; Nozoye, T.; Nishizawa, N.K. Iron transport and its regulation in plants. Free Radic. Biol. Med. 2019, 133, 11-20. [CrossRef]

6. Gao, F.; Robe, K.; Gaymard, F.; Izquierdo, E.; Dubos, C. The Transcriptional Control of Iron Homeostasis in Plants: A Tale of bHLH Transcription Factors? Front. Plant Sci. 2019, 10, 6. [CrossRef]

7. Riaz, N.; Guerinot, M.L. All together now: Regulation of the iron deficiency response. J. Exp. Bot. 2021, 72, 2045-2055. [CrossRef]

8. Gao, F.; Dubos, C. Transcriptional integration of plant responses to iron availability. J. Exp. Bot. 2021, 72, 2056-2070. [CrossRef]

9. Kobayashi, T.; Itai, R.N.; Aung, M.S.; Senoura, T.; Nakanishi, H.; Nishizawa, N.K. The rice transcription factor IDEF1 directly binds to iron and other divalent metals for sensing cellular iron status. Plant J. 2011, 69, 81-91. [CrossRef]

10. Kobayashi, T.; Nagasaka, S.; Senoura, T.; Itai, R.N.; Nakanishi, H.; Nishizawa, N.K. Iron-binding haemerythrin RING ubiquitin ligases regulate plant iron responses and accumulation. Nat. Commun. 2013, 4, 2792. [CrossRef]

11. Selote, D.; Samira, R.; Matthiadis, A.; Gillikin, J.W.; Long, T.A. Iron-Binding E3 Ligase Mediates Iron Response in Plants by Targeting Basic Helix-Loop-Helix Transcription Factors. Plant Physiol. 2015, 167, 273-286. [CrossRef]

12. Stone, S.L. The role of ubiquitin and the $26 \mathrm{~S}$ proteasome in plant abiotic stress signaling. Front. Plant Sci. 2014, 5, 135. [CrossRef]

13. Zhang, H.; Li, Y.; Yao, X.; Liang, G.; Yu, D. POSITIVE REGULATOR OF IRON HOMEOSTASIS1, OsPRI1, Facilitates Iron Homeostasis. Plant Physiol. 2017, 175, 543-554. [CrossRef]

14. Kobayashi, T.; Ozu, A.; Kobayashi, S.; An, G.; Jeon, J.-S.; Nishizawa, N.K. OsbHLH058 and OsbHLH059 transcription factors positively regulate iron deficiency responses in rice. Plant Mol. Biol. 2019, 101, 471-486. [CrossRef]

15. Zhang, H.; Li, Y.; Pu, M.; Xu, P.; Liang, G.; Yu, D. Oryza sativa POSITIVE REGULATOR OF IRON DEFICIENCY RESPONSE 2 (OsPRI2) and OsPRI3 are involved in the maintenance of Fe homeostasis. Plant Cell Environ. 2020, 43, 261-274. [CrossRef]

16. Ogo, Y.; Itai, R.N.; Kobayashi, T.; Aung, M.S.; Nakanishi, H.; Nishizawa, N.K. OsIRO2 is responsible for iron utilization in rice and improves growth and yield in calcareous soil. Plant Mol. Biol. 2011, 75, 593-605. [CrossRef]

17. Long, T.A.; Tsukagoshi, H.; Busch, W.; Lahner, B.; Salt, D.E.; Benfey, P.N. The bHLH Transcription Factor POPEYE Regulates Response to Iron Deficiency in Arabidopsis Roots. Plant Cell 2010, 22, 2219-2236. [CrossRef]

18. Zheng, L.; Ying, Y.; Wang, L.; Wang, F.; Whelan, J.; Shou, H. Identification of a novel iron regulated basic helix-loop-helix protein involved in Fe homeostasis in Oryza sativa. BMC Plant Biol. 2010, 10, 166. [CrossRef]

19. Wang, W.; Ye, J.; Ma, Y.; Wang, T.; Shou, H.; Zheng, L. OsIRO3 Plays an Essential Role in Iron Deficiency Responses and Regulates Iron Homeostasis in Rice. Plants 2020, 9, 1095. [CrossRef]

20. Wang, F.; Itai, R.N.; Nozoye, T.; Kobayashi, T.; Nishizawa, N.K.; Nakanishi, H. The bHLH protein OsIRO3 is critical for plant survival and iron (Fe) homeostasis in rice (Oryza sativa L.) under Fe-deficient conditions. Soil Sci. Plant Nutr. 2020, 66, 579-592. [CrossRef]

21. ABARES, Agricultural Forecasts and Outlook: September 2020. 2020. Available online: https://doi.org/10.25814/5f3caa10eee79 (accessed on 8 October 2020).

22. Chen, Y.; Barak, P. Iron Nutrition of Plants in Calcareous Soils. Adv. Agron. 1982, 35, 217-240. [CrossRef]

23. Lindsay, W.L. Soil and plant relationships associated with iron deficiency with emphasis on nutrient interactions. J. Plant Nutr. 1984, 7, 489-500. [CrossRef]

24. Adamski, N.M.; Borrill, P.; Brinton, J.; A Harrington, S.; Marchal, C.; Bentley, A.R.; Bovill, W.D.; Cattivelli, L.; Cockram, J.; Contreras-Moreira, B.; et al. A roadmap for gene functional characterisation in crops with large genomes: Lessons from polyploid wheat. eLife 2020, 9, e55646. [CrossRef]

25. The International Wheat Genome Sequencing Consortium (IWGSC); Appels, R.; Eversole, K.; Stein, N.; Feuillet, C.; Keller, B.; Rogers, J.; Pozniak, C.J.; Choulet, F.; Distelfeld, A.; et al. Shifting the limits in wheat research and breeding using a fully annotated reference genome. Science 2018, 361, eaar7191. [CrossRef] [PubMed]

26. Bolser, D.M.; Kerhornou, A.; Walts, B.; Kersey, P. Triticeae Resources in Ensembl Plants. Plant Cell Physiol. 2015, 56, e3. [CrossRef] [PubMed]

27. Bonneau, J.; O’Brien, M.; Plett, D.C.; Johnson, A.A.T. Genetic Pathways Important for Iron Nutrition and Biofortification of Bread Wheat. Annu. Plant Rev. Online 2019, 237-272. [CrossRef]

28. Wang, M.; Gong, J.; Bhullar, N.K. Iron deficiency triggered transcriptome changes in bread wheat. Comput. Struct. Biotechnol. J. 2020, 18, 2709-2722. [CrossRef]

29. Beasley, J.T.; Bonneau, J.P.; Johnson, A.A.T. Characterisation of the nicotianamine aminotransferase and deoxymugineic acid synthase genes essential to Strategy II iron uptake in bread wheat (Triticum aestivum L.). PLoS ONE 2017, 12, e0177061. [CrossRef]

30. Bonneau, J.; Baumann, U.; Beasley, J.; Julien, B.; Johnson, A.A.T. Identification and molecular characterization of the nicotianamine synthase gene family in bread wheat. Plant Biotechnol. J. 2016, 14, 2228-2239. [CrossRef] 
31. Sharma, S.; Kaur, G.; Kumar, A.; Meena, V.; Kaur, J.; Pandey, A.K. Overlapping transcriptional expression response of wheat zinc-induced facilitator-like transporters emphasize important role during Fe and Zn stress. BMC Mol. Biol. 2019, $20,1-17$. [CrossRef]

32. Sharma, S.; Kaur, G.; Kumar, A.; Meena, V.; Ram, H.; Kaur, J.; Pandey, A.K. Gene Expression Pattern of Vacuolar-Iron TransporterLike (VTL) Genes in Hexaploid Wheat during Metal Stress. Plants 2020, 9, 229. [CrossRef] [PubMed]

33. Wang, M.; Kawakami, Y.; Bhullar, N.K. Molecular Analysis of Iron Deficiency Response in Hexaploid Wheat. Front. Sustain. Food Syst. 2019, 3, 67. [CrossRef]

34. Kaur, G.; Shukla, V.; Kumar, A.; Kaur, M.; Goel, P.; Singh, P.; Shukla, A.; Meena, V.; Kaur, J.; Singh, J.; et al. Integrative analysis of hexaploid wheat roots identifies signature components during iron starvation. J. Exp. Bot. 2019, 70, 6141-6161. [CrossRef]

35. Ramirez-Gonzalez, R.H.; Borrill, P.; Lang, D.; Harrington, S.A.; Brinton, J.; Venturini, L.; Davey, M.; Jacobs, J.; Van Ex, F.; Pasha, A.; et al. The transcriptional landscape of polyploid wheat. Science 2018, 361, eaar6089. [CrossRef] [PubMed]

36. Kawahara, Y.; De La Bastide, M.; Hamilton, J.P.; Kanamori, H.; McCombie, W.R.; Ouyang, S.; Schwartz, D.C.; Tanaka, T.; Wu, J.; Zhou, S.; et al. Improvement of the Oryza sativa Nipponbare reference genome using next generation sequence and optical map data. Rice 2013, 6, 4. [CrossRef] [PubMed]

37. Alaux, M.; International Wheat Genome Sequencing Consortium; Rogers, J.; Letellier, T.; Flores, R.; Alfama, F.; Pommier, C.; Mohellibi, N.; Durand, S.; Kimmel, E.; et al. Linking the International Wheat Genome Sequencing Consortium bread wheat reference genome sequence to wheat genetic and phenomic data. Genome Biol. 2018, 19, 111. [CrossRef] [PubMed]

38. Howe, K.L.; Contreras-Moreira, B.; De Silva, N.; Maslen, G.; Akanni, W.; Allen, J.; Alvarez-Jarreta, J.; Barba, M.; Bolser, D.M.; Cambell, L.; et al. Ensembl Genomes 2020—enabling non-vertebrate genomic research. Nucleic Acids Res. 2020, 48, D689-D695. [CrossRef]

39. Boguski, M.S.; Lowe, T.M.; Tolstoshev, C.M. dbEST-Database for "expressed sequence tags". Nat. Genet. 1993, 4, 332-333. [CrossRef] [PubMed]

40. Camacho, C.; Coulouris, G.; Avagyan, V.; Ma, N.; Papadopoulos, J.S.; Bealer, K.; Madden, T.L. BLAST+: Architecture and applications. BMC Bioinform. 2009, 10, 421. [CrossRef]

41. Cock, P.J.A.; Chilton, J.M.; Grüning, B.; Johnson, J.E.; Soranzo, N. NCBI BLAST+ integrated into Galaxy. GigaScience 2015, 4, 39 [CrossRef]

42. Berardini, T.Z.; Reiser, L.; Li, D.; Mezheritsky, Y.; Muller, R.; Strait, E.; Huala, E. The Arabidopsis information resource: Making and mining the "gold standard" annotated reference plant genome. Genesis 2015, 53, 474-485. [CrossRef]

43. Guindon, S.; Dufayard, J.-F.; Lefort, V.; Anisimova, M.; Hordijk, W.; Gascuel, O. New Algorithms and Methods to Estimate Maximum-Likelihood Phylogenies: Assessing the Performance of PhyML 3.0. Syst. Biol. 2010, 59, 307-321. [CrossRef] [PubMed]

44. Blum, M.; Chang, H.-Y.; Chuguransky, S.; Grego, T.; Kandasaamy, S.; Mitchell, A.; Nuka, G.; Paysan-Lafosse, T.; Qureshi, M.; Raj, S.; et al. The InterPro protein families and domains database: 20 years on. Nucleic Acids Res. 2021, 49, D344-D354. [CrossRef]

45. Schreiber, A.W.; Sutton, T.; A Caldo, R.; Kalashyan, E.; Lovell, B.; Mayo, G.; Muehlbauer, G.J.; Druka, A.; Waugh, R.; Wise, R.P.; et al. Comparative transcriptomics in the Triticeae. BMC Genom. 2009, 10, 285. [CrossRef] [PubMed]

46. Sears, E.R. The Aneuploids of Common Wheat; University of Missouri, College of Agriculture, Agricultural Experiment Station: Columbia, MO, USA, 1954; Volume 572, pp. 1-58.

47. Vandesompele, J.; De Preter, K.; Pattyn, F.; Poppe, B.; Van Roy, N.; De Paepe, A.; Speleman, F. Accurate normalization of real-time quantitative RT-PCR data by geometric averaging of multiple internal control genes. Genome Biol. 2002, 3, 3. [CrossRef] [PubMed]

48. Borrill, P.; Ramirez-Gonzalez, R.; Uauy, C. expVIP: A Customizable RNA-seq Data Analysis and Visualization Platform. Plant Physiol. 2016, 170, 2172-2186. [CrossRef]

49. Harrington, S.A.; Backhaus, A.E.; Singh, A.; Hassani-Pak, K.; Uauy, C. The Wheat GENIE3 Network Provides BiologicallyRelevant Information in Polyploid Wheat. G3 Genes Genomes Genet. 2020, 10, 3675-3686. [CrossRef]

50. Pires, N.; Dolan, L. Origin and Diversification of Basic-Helix-Loop-Helix Proteins in Plants. Mol. Biol. Evol. 2009, 27, 862-874. [CrossRef] [PubMed]

51. Toledo-Ortiz, G.; Huq, E.; Quail, P.H. The Arabidopsis Basic/Helix-Loop-Helix Transcription Factor Family [W]. Plant Cell 2003, 15, 1749-1770. [CrossRef]

52. Buck, M.J.; Atchley, W.R. Phylogenetic Analysis of Plant Basic Helix-Loop-Helix Proteins. J. Mol. Evol. 2003, 56, 742-750. [CrossRef]

53. Kagale, S.; Rozwadowski, K. EAR motif-mediated transcriptional repression in plants: An underlying mechanism for epigenetic regulation of gene expression. Epigenetics 2011, 6, 141-146. [CrossRef] [PubMed]

54. Li, Y.; Lei, R.; Pu, M.; Cai, Y.; Lu, C.; Li, Z.; Liang, G. bHLH11 negatively regulates Fe homeostasis by its EAR motifs recruiting corepressors in Arabidopsis. BioRxiv 2020. [CrossRef]

55. Spielmann, J.; Vert, G. The many facets of protein ubiquitination and degradation in plant root iron-deficiency responses. J. Exp. Bot. 2021, 72, 2071-2082. [CrossRef]

56. Sheriff, S.; Hendrickson, W.A.; Smith, J.L. Structure of myohemerythrin in the azidomet state at $1.71 .3 \AA$ A resolution. J. Mol. Biol. 1987, 197, 273-296. [CrossRef]

57. Rodríguez-Celma, J.; Chou, H.; Kobayashi, T.; Long, T.A.; Balk, J. Hemerythrin E3 Ubiquitin Ligases as Negative Regulators of Iron Homeostasis in Plants. Front. Plant Sci. 2019, 10, 98. [CrossRef] [PubMed] 
58. Chaudhary, S.; Khokhar, W.; Jabre, I.; Reddy, A.S.N.; Byrne, L.J.; Wilson, C.M.; Syed, N.H. Alternative Splicing and Protein Diversity: Plants Versus Animals. Front. Plant Sci. 2019, 10, 708. [CrossRef]

59. Dong, C.; He, F.; Berkowitz, O.; Liu, J.; Cao, P.; Tang, M.; Shi, H.; Wang, W.; Li, Q.; Shen, Z.; et al. Alternative Splicing Plays a Critical Role in Maintaining Mineral Nutrient Homeostasis in Rice (Oryza sativa). Plant Cell 2018, 30, 2267-2285. [CrossRef] [PubMed]

60. Zhang, W.; Du, B.; Liu, D.; Qi, X. Splicing factor SR34b mutation reduces cadmium tolerance in Arabidopsis by regulating iron-regulated transporter 1 gene. Biochem. Biophys. Res. Commun. 2014, 455, 312-317. [CrossRef]

61. Schuler, M.; Rellán-Álvarez, R.; Fink-Straube, C.; Abadía, J.; Bauer, P. Nicotianamine Functions in the Phloem-Based Transport of Iron to Sink Organs, in Pollen Development and Pollen Tube Growth in Arabidopsis. Plant Cell 2012, 24, 2380-2400. [CrossRef]

62. Pfeifer, M.; Kugler, K.G.; Sandve, S.R.; Zhan, B.; Rudi, H.; Hvidsten, T.R.; Mayer, K.F.X.; Olsen, O.-A. International Wheat Genome Sequencing Consortium Genome interplay in the grain transcriptome of hexaploid bread wheat. Science 2014, 345, 1250091. [CrossRef] [PubMed]

63. Choulet, F.; Alberti, A.; Theil, S.; Glover, N.; Barbe, V.; Daron, J.; Pingault, L.; Sourdille, P.; Couloux, A.; Paux, E.; et al. Structural and functional partitioning of bread wheat chromosome 3B. Science 2014, 345, 1249721. [CrossRef] [PubMed]

64. Kobayashi, T.; Ogo, Y.; Itai, R.N.; Nakanishi, H.; Takahashi, M.; Mori, S.; Nishizawa, N.K. The transcription factor IDEF1 regulates the response to and tolerance of iron deficiency in plants. Proc. Natl. Acad. Sci. USA 2007, 104, 19150-19155. [CrossRef] [PubMed]

65. McElver, J.; Tzafrir, I.; Aux, G.; Rogers, R.; Ashby, C.; Smith, K.; Thomas, C.; Schetter, A.; Zhou, Q.; A Cushman, M.; et al. Insertional mutagenesis of genes required for seed development in Arabidopsis thaliana. Genetics 2001, 159, 1751-1763. [PubMed] 